\title{
Light heterogeneity affects understory plant diversity in temperate forests confirming the heterogeneity-diversity hypothesis
}

\author{
Jan Helbach ${ }^{1}$, Julian Frey ${ }^{1}$, Christian Messier $^{2}$, and Michael Scherer-Lorenzen ${ }^{1,1}$ \\ ${ }^{1}$ University of Freiburg \\ ${ }^{2}$ Universite du Quebec a Montreal
}

April 28, 2020

\begin{abstract}
One of the most important drivers of the coexistence of species is the resource heterogeneity of a certain environment. Thus, many studies in different ecosystems have been carried out to test whether species richness is affected by resource heterogeneity. To date, only few studies have measured light and soil resources heterogeneity in forests to investigate its influence on plant diversity. In this study, the aim was to determine (1) which resources have major influences on forest understory plant diversity; (2) the influence of the forest canopy on the heterogeneous distribution of light and soil resources; (3) whether heterogeneity of resources increases understory plant species richness; and (4) if stand structural complexity is an indicator for understory plant species richness. Measures of stand structural complexity were obtained through inventories and remote sensing techniques in 135 study plots of temperate forests, established along a gradient of forest structural complexity. We surveyed vegetation, measured light conditions and soil properties six times in each of all plots. We calculated the standard deviations of these parameters to receive a measure of heterogeneity. Results showed that heterogeneity of light and soil C:N ratio increases with increasing stand structural complexity, increasing light heterogeneity leads to increased understory plant species richness, and finally, an increase of stand structural diversity predicts an increase in understory plant diversity. The study clearly shows that resource heterogeneity theory plays a major role in the coexistence of understory plant species and hence its diversity. These results suggest that understory plant diversity could be increased in forests managed by single tree harvesting by spatially varying the quantities of trees to be logged to create a more heterogeneous understory light environment.
\end{abstract}

Light heterogeneity affects understory plant diversity in temperate forests confirming the heterogeneitydiversity hypothesis

Running title: Confirming heterogeneity-diversity hypothesis of light in forests

\section{Jan Helbach$^{1}$, Julian Frey ${ }^{2}{ }^{*}$, Christian Messier ${ }^{3}$ \& Michael Scherer-Lorenzen ${ }^{1}$}

Contact person: Jan Helbach (jan.helbach@biologie.uni-freiburg.de), University of Freiburg, Schänzlestraße 1, 79104 Freiburg, Germany

1. Geobotany, Faculty of Biology, University of Freiburg, Schänzlestr. 1, 79104 Freiburg, Germany

2. Chair of Remote Sensing and Landscape Information Systems, Faculty of Environment and Natural Resources, University of Freiburg, Tennenbacherstr. 4, 79106 Freiburg, Germany

3. CEF, ISFORT, Université du Québec en Outaouais et à Montréal, Montréal, Canada

*Current address: Chair of Forest Growth, Faculty of Environment and Natural Resources, University of Freiburg, Tennenbacherstr. 4, 79106 Freiburg, Germany

Keywords: understory diversity, environmental heterogeneity, stand structural diversity, coexistence, community ecology, ConFoBi 
Abstract One of the most important drivers of the coexistence of species is the resource heterogeneity of a certain environment. Thus, many studies in different ecosystems have been carried out to test whether species richness is affected by resource heterogeneity. To date, only few studies have measured light and soil resources heterogeneity in forests to investigate its influence on plant diversity. In this study, the aim was to determine (1) which resources have major influences on forest understory plant diversity; (2) the influence of the forest canopy on the heterogeneous distribution of light and soil resources; (3) whether heterogeneity of resources increases understory plant species richness; and (4) if stand structural complexity is an indicator for understory plant species richness. Measures of stand structural complexity were obtained through inventories and remote sensing techniques in 135 study plots of temperate forests, established along a gradient of forest structural complexity. We surveyed vegetation, measured light conditions and soil properties six times in each of all plots. We calculated the standard deviations of these parameters to receive a measure of heterogeneity. Results showed that heterogeneity of light and soil C:N ratio increases with increasing stand structural complexity, increasing light heterogeneity leads to increased understory plant species richness, and finally, an increase of stand structural diversity predicts an increase in understory plant diversity. The study clearly shows that resource heterogeneity theory plays a major role in the coexistence of understory plant species and hence its diversity. These results suggest that understory plant diversity could be increased in forests managed by single tree harvesting by spatially varying the quantities of trees to be logged to create a more heterogeneous understory light environment. Introduction

\section{Environmental heterogeneity hypothesis}

Why do species coexist? It is well accepted that species with the same habitat requirements cannot coexist (Hardin 1960). However, the large number of autotrophic plant species that co-occur in certain ecosystems and that rely on the same limited set of abiotic resources (light, water, nutrients, space) seem to contradict this theory. Hence, many ecologists are preoccupied with this contradiction (Chesson 2000, Wright 2002, Tokeshi 2009, Angert et al. 2009). Some argue that competitive exclusion may be slowed down by top down or bottom up control-mechanisms or disturbance events (Connell 1978). Others have suggested alternative mechanisms where competitive exclusion can be avoided by environmental heterogeneity of habitats, which increases the number of available niches to which different species may be adapted (Hutchinson 1957, MacArthur and MacArthur 1961, Macarthur and Levins 1967, Silvertown 2004, Sedio and Ostling 2013). This "environmental heterogeneity hypothesis" as a promoter of species coexistence and hence a driver for species diversity in ecosystems is now a widely accepted theory (Chesson 2000, Allouche et al. 2012, Stein et al. 2014). Many studies testing this hypothesis have investigated open land habitats (Morzaria-Luna et al. 2004, Lundholm 2009, Bergholz et al. 2017), or focused on landscape level measures of heterogeneity in abiotic or biotic conditions (see studies in Stein et al. 2014). In forest habitats, which show a rather high within-habitat heterogeneity due to the complex canopy architecture of trees, studies have included vegetation structure, dead wood occurrence, management regimes, wind throws and other disturbances, differences in overstory species richness, or abiotic conditions as proxies for heterogeneity and many different groups of organism ranging from birds to plants as biodiversity variables (e.g. MacArthur and MacArthur 1961, Richard et al. 2000, Taboada et al. 2008, Tamme et al. 2010, Bartels and Chen 2010). The effect of environmental heterogeneity on diversity will also depend on the spatial scale investigated, which could range from centimetres, metres (i.e. patch scale, e.g. safe sites for seed germination, or sun flecks in the forest understory) to kilometres (i.e. landscape scale, e.g. altitude and climatic belts).

\section{Forest structures and resource availability}

Even-aged, monospecific stands that are favoured after clearcutting often have a homogeneous three-dimensional canopy structure which might, therefore, reduce the heterogeneity in resource availability for plants (Fedrowitz et al. 2014). In Central Europe, management has shifted to single tree harvesting since the 90's to obtain more continuous cover forests (Gustafsson et al. 2019). This management regime affects light quantity (Forrester et al. 2018) and heterogeneity and, consequently, understory plant composition and density (Bengtsson et al. 2000, Getzin et al. 2012, Duguid and Ashton 2013). In addition, different tree species produce different crown structures (Ampoorter et al. 2015, 2016) and react differently to disturbances such as wind and snow 
damage, or pest outbreaks (Burton et al. 2014, Hilmers et al. 2018). More recently retention forestry has been promoted to enhance structural complexity in rather homogeneous, even-aged stands to favour forest biodiversity (Gustafsson et al. 2012, 2019). Understory plant species composition, species richness, and functional diversity have been shown to be affected by retention measures (Halpern et al. 2012, Lindenmayer et al. 2012). Retention forestry alters microclimate and resource availability across spatial and temporal scales, potentially affecting understory plant composition and density (Aubry et al. 2009, Kriebitzsch et al. 2013). Introducing structural diversity by creating gaps, or by leaving habitat trees, will affect light quality and quantity, wind speed and air humidity, soil temperature and moisture, litter input, and hence nutrient availability at the forest floor (Abd Latif and Blackburn 2010). In addition, these abiotic conditions will also vary across several temporal scales (daily fluctuations, seasonal changes, year-to-year variation, Leuschner et al. 2017). In particular, the spatio-temporal variability of light quantity at the forest floor is usually greater in structurally more complex forest stands (Liira et al. 2007). Thus the complex interplay of these changes results in an altered resource availability for plants (light, nutrients, water), and hence provides competitive advantages to certain species over others. Understory plant species composition, species richness, and functional diversity have been shown to be affected by retention measures (Halpern et al. 2012, Lindenmayer et al. 2012).

\section{Aim of the study and hypotheses}

The aim of this study was to determine (1) the relative importance of light and nutrient soil drivers on affecting understory plant species richness, (2) whether structural complexity of the tree canopy induces heterogeneity in these abiotic factors at the patch scale, and (3) whether such heterogeneity affects understory plant species richness. So far, studies that have investigated the habitat-heterogeneity hypothesis for forest understory plant species actually have rarely tested whether species richness increases when resources are heterogeneously distributed on such a small scale (Reich et al. 2012, Su et al. 2019).

With respect to the above- mentioned research questions, we hypothesize that (H1) light is a more important driver of understory plant species richness than soil nutrient factors, that (H2) an increase in stand structural complexity results in an increase in light and soil resource heterogeneity, and that (H3) understory plant diversity increases with increasing resource heterogeneity. If hypotheses (H2) and (H3) are verified, we will further test the hypothesis that $(\mathrm{H} 4)$ one can use measures of stand structural complexity to predict understory plant diversity (Fig. 1).

To test these hypotheses, we determined understory plant species richness and analyzed the spatio-temporal availability of light and soil nutrient resources in temperate forest stands along a gradient of stand structural complexity which had been created through different management interventions in the past.

Material and methods

\section{Study site}

Field sampling was carried out in the Central and Southern Black Forest in southwest Germany. The 135 research plots each measured $100 \times 100 \mathrm{~m}$ in size with a minimum distance of $750 \mathrm{~m}$ between plots. These plots belong to the 'Conservation of forest biodiversity in multiple-use landscapes of Central Europe' research project (Storch et al. 2020, Fig. 2), and are all located in temperate mountainous forests between $434 \mathrm{~m}$ and $1334 \mathrm{~m}$ above sea level. The annual average temperature is about $6.9{ }^{\circ} \mathrm{C}$ with a yearly average precipitation of $1205 \mathrm{~mm}$ (climate station of the city of Titisee-Neustadt, www.climate-data.org, accessed 2020/2/16).

Forests are dominated by Abies alba, Fagus sylvativa andPicea abies growing on cambisol, umbrisol and podzoles. The forest stands are managed with continuous cover forestry (Gustaffson et al. 2019). The bedrock consists of gneiss and granite in the west, with lower Triassic sandstone and middle and upper Triassic limestones towards the east.

We selected the plots to cover a large landscape and forest structure gradient. For the landscape gradient, we set three categories of forest cover within a $25 \mathrm{~km}$ radius from the centre of each plot: $<50 \%, 50-75 \%$ and $>75 \%$ forest coverage estimated by raster data (state agency of spatial information and rural development 
of Baden-Württemberg, accessed 2016). Additionally, we obtained the forest structure gradient based on the number of standing dead trees assessed from aerial images ((state agency of spatial information and rural development of Baden-Württemberg, accessed 2016): 0, 1-9, >10. Detailed information can be found in Storch et al. (2020).

\section{Study design and field Sampling}

The field sampling took place during the growing season, from August 2016 to July 2018. Presence or absence of all vascular plants was recorded within each of the $100 \times 100 \mathrm{~m}$ plots (plot level). To obtain cover estimates of plant species, and to be able to quantify resource heterogeneity within plots, we additionally established six $5 \times 5 \mathrm{~m}$ subplots located within each plot (subplot level). The cover was visually recorded as one of three categories (1): $1-5 \%$ cover or less than 15 individuals, (2): $6-25 \%$ cover or more than 15 individuals, or (3): $26-100 \%$ cover. For calculations, cover estimates were transformed to $2.5 \%, 15 \%$ and $35 \%$, respectively. To more precisely resolve the uneven cover distribution, these cover categories were subdivided on a quasi-logarithmic scale. We separated the cover into two height strata. The herb and shrub layer comprised all vascular plants and all shrubs or woody species smaller than $5 \mathrm{~m}$ in height, subsequently called understory vegetation. The tree layer comprised all species taller than $5 \mathrm{~m}$. Species names follow the nomenclature of Rothmaler (2017).

Additionally, at each plot centre a single terrestrial laser scan (TLS) was conducted between September 2017 and May 2018. Each scan was carried out with a Faro Focus 3D 120 (Faro Technologies Inc., Lake Mary, USA) laser scanner set to $0.044^{\circ}$ angular resolution. A full $360^{\circ}$ horizontal and $150^{\circ}$ vertical angular range was covered, resulting in a maximum of 29 million points per scan. The scanner was placed on a tripod at $1.3 \mathrm{~m}$ from the ground.

\section{Soil analyses}

Directly after recording the plant species, on each subplot three soil cores of $1 \mathrm{~cm}$ diameter were taken in a systematic grid and mixed together. Soil samples were sieved to a minimum of $2 \mathrm{~mm}$ grain size. To determine water content, $5 \mathrm{~g}$ of soil was dried for 48 hours at $105^{\circ} \mathrm{C}$. Ammonium and nitrate were extracted from $10 \mathrm{~g}$ of wet soil with $25 \mathrm{ml} 1 \mathrm{~mol} \mathrm{KCl}$ solution, shaking for 30 minutes. In the case of shallow soil, analyses were made with less soil, keeping the soil:solution ratio constant to avoid differences in extraction strength. If there was too little soil to keep the soil:solution ratio constant, a correction factor was empirically determined to account for the higher extraction strength. After filtration with the $\mathrm{KCl}$ extract, we measured the $\mathrm{pH}$-value with a $\mathrm{pH}$-electrode (719 S Titrino, Metrohm, Switzerland). With the remaining solution, we measured ammonium and nitrate with a microplate reader (Synergy mx, Biotek Instruments, Germany). We determined ammonium cholorometrically according to Baethgen and Alley (1989) and nitrate according to Miranda et al. (2001). Both concentrations were expressed as ppm of dry soil.

We analyzed concentrations of 20 cations and of phosphorous with an inductively coupled plasma spectrometer (ICP-OES, Spectroblue Ti, Spectro Analytical Instruments GmbH, Germany). As standards, we used a 20-cation solution (ICP multielement standard solution IV Merk KgaA, Germany) and a P solution (Singleelement ICP standard solution, Phosphorus, Carl Roth GmbH + Co. KG, Germany). Only those cations known to be macro- or micro-nutrients for plants were further considered. To achieve this, we extracted $5 \mathrm{~g}$ wet soil with Mehlich 1 solution (Mehlich, A 1953). Samples exceeding determination threshold were diluted and re-measured.

We dried an aliquot of soil at $60{ }^{\circ} \mathrm{C}$ and milled with a pebble mill for $1.5 \mathrm{~min} .50 \mu \mathrm{g}$ were weighed in tin capsules to determine $\mathrm{C}$ and $\mathrm{N}$ content with a combustion gas detector (Vario EL cube, Elementar, Germany).

\section{Light analysis}

We determined light environment at the subplot level with hemispheric photography taken with a Nikon D90 (Nikon, Tokyo, Japan) camera equipped with a Sigma 4,5 mm F2,8 EX DC HSM circular fisheye-lens (Sigma, Kawasaki, Japan). The camera was placed in the centre of the subplots $1 \mathrm{~m}$ above the forest floor 
with the camera lens facing north and levelled horizontally. The hemispheric photographs were taken in 2018, one year after the major plant survey. Missing values are caused by tree removal through logging on the plot or the absence of plot markings. The photos were prepared with an image processing software (Darktable version 2.4.2, GPL 3.0 (C)2017, Darktable team) to adjust lighting. We calculated the diffuse light index (DLI) with the software Hemisfer (WSL, Schleppi et al. 2007). As a measure of spatial light heterogeneity, we calculated the standard deviation of DLI from the six subplots.

\section{Measures of stand structural complexity}

As the structure of the canopy influences heterogeneity of light conditions at the forest floor (and hence spatial-temporal light availability for understory plants), it is important to find measures which best represent the structural complexity of the canopy. Three measures were used in this study to quantify canopy structural complexity, which is hypothesized to affect resource heterogeneity and thus understory plant species diversity. First, we calculated the standard deviation of diameter at breast height (DBHsd) for all trees with DBH > $7 \mathrm{~cm}$ from the full inventory of each plot (Storch et. al 2020).

Second, we used a public dataset of aerial image flights with $20 \mathrm{~cm}$ pixel resolution and $60 \%$ forward and $30 \%$ sideward image overlaps to generate a digital surface model (DSM) using a structure from motion workflow (equivalent to Zielewska-Büttner et al. 2016) using Agisoft Photoscan commercial software, v. 1.3.4, AgiSoft, St Petersburg, 2017). From the resulting DSM with a resolution of $40 \mathrm{~cm}$, we computed the Terrain Ruggedness Index (TRI, Wilson et al. 2007), as a measure of the geometric complexity of the crown surface.

Third, to measure the geometric complexity of the distribution of plant material within the stand, we used the data from terrestrial laser scans to compute the index of stand structural complexity (SSCI) following the approach suggested by Ehbrecht et al. (2017).

\section{Measures of environmental heterogeneity}

To analyze environmental heterogeneity, we calculated the standard deviation of measured environmental variables for the six subplots of each plot. The selected variables were: DLI, pH, total carbon, nitrogen, C:N-ratio, phosphorous and potassium.

\section{Classification of forest communities}

The 135 plots harboured a total of 332 vascular plant species, with species richness values ranging from two to 71 . We classified the different forest communities according to their plant species composition. We $\log$ transformed and scaled the relevé data via the Hellinger method prior to data analysis (Legendre and Gallagher 2001). We calculated dissimilarities in species composition using the Bray-Curtis Index and created hierarchical cluster dendrograms using option "ward.D2" for Ward clustering within the R package Vegan (Murtagh and Legendre 2014). To find the optimal numbers of clusters, we used the clustering method of the R package NbClust (Charrad et al. 2014); we chose "NULL" for distance, "ward.D2" as method, and "kl" as index.

This resulted in four clusters of forest plant communities that clearly differ in species composition, due to environmental differences, such as soil chemistry, altitude and slope, as well as tree species richness (Table S1, Fig. S2). Therefore, we tested our hypotheses with both the entire dataset and these four forest types separately.

\section{Statistical analyses}

We performed all statistical tests in $\mathrm{R}$ version 3.6.1 ( $\mathrm{R}$ Core Team 2019 p.). To fit distributions of response variables, we used the fitdistplus-package (Delignette-Muller and Dutang 2015). The distribution for species richness was negative binomial (on all levels). We tested if DLI, pH, total nitrogen, total carbon, C:N-ratio, ammonium, nitrate, phosphorous, potassium, average slope, aspect, and altitude affected species richness at the subplot level using a generalized linear mixed model from the R-package lme4 (Bates et al. 2015) with a negative binomial distribution from the R-package MASS (Venables and Ripley 2002). Conditional 
$\mathrm{R}^{2}$-values were then calculated (Nakagawa and Schielzeth 2013). The same analyses were performed at the plot level for those which were significant at the subplot level using generalized linear models (GLM) where the response was negative binomial distribution. Additionally, we determined if the structural complexity measures DBHsd, TRI and SSCI affected any of the above-mentioned environmental heterogeneity variables using GLMs, where light heterogeneity was Gamma distributed while all other variables were log-normally distributed. Next, we tested if species richness at an aggregate level is affected by the environmental heterogeneity variables (see above) using the GLM negative binomial distribution from the R-package MASS (Venables and Ripley 2002). For all heterogeneity variables we included the corresponding absolute values to test whether possible effects are only induced by quantity. Finally, we tested if the structural complexity variables had any effect on species richness. This was tested using the GLM negative binomial distribution from the R-package MASS (Venables and Ripley 2002). To determine the model of best fit for each approach, model selection was performed with R-package MuMIn (Bartoń 2019). The package computes all possible models of the given variables. The model of lowest Akaikes information criterion (AIC) is taken as valid. We included variables which are ecologically important, and which do not interfere with each other: forest community, DLI, soil-pH, C:N-ratio, phosphorous, average slope, aspect and altitude.

Results

\section{Environmental drivers of understory species richness (Hypothesis 1)}

After model selection, three variables explained $22.6 \%$ of the total variation: DLI explained most with $14.4 \%$, then $\mathrm{pH}$ with $6.5 \%$ and then $\mathrm{C}: \mathrm{N}$ ratio with $1.7 \%$ at the subplot level. Plant species richness generally increased with light quantity up to a maximum and then slightly decreased $\left(\mathrm{p}<0.001, \mathrm{r}^{2}=0.65\right.$, Conditional R-GLMM ${ }^{2}$, see Fig. 3), although data coverage above $40 \%$ light availability is arguably low. Understory species richness showed a hump-shaped relationship with soil $\mathrm{pH}$, with a maximum at $\mathrm{pH} 4.8$ (p $<0.001 \mathrm{r}^{2}=0.45$. Conditional R-GLMM ${ }^{2}$ ). There was a negative relationship between soil C:N-ratio and species richness $\left(\mathrm{p}=0.007, \mathrm{r}^{2}=0.65\right.$, Conditional $\mathrm{R}$-GLMM ${ }^{2}$ ). All other variables did not correlate with species richness.

\section{Effects of structural complexity on environmental heterogeneity (Hypothesis 2)}

An increase in structural complexity of the forest canopy resulted in increasing light heterogeneity for SSCI $\left(\mathrm{p}=0.008, \mathrm{r}^{2}=0.28\right.$, see Fig. 4$)$, TRI $\left(\mathrm{p}=0.017, \mathrm{r}^{2}=0.42\right.$, not shown $)$ and DBHsd $\left(\mathrm{p}=0.007, \mathrm{r}^{2}=\right.$ 0.44 , not shown). The soil parameter C:N ratio correlated positively to SSCI $\left(\mathrm{p}=0.0002, \mathrm{r}^{2}=0.14\right)$ and DBHsd $\left(\mathrm{p}=0.02, \mathrm{r}^{2}=0.44\right)$, and potassium increased positively with SSCI $\left(\mathrm{p}=0.043, \mathrm{r}^{2}=0.41\right)$ but after removing extreme values (excluding all values above $1.5 *$ interquartile range) no effect was found. During model selection forest communities did not remain in the model of best fit and thus are not shown here.

Effects of environmental heterogeneity on plant species richness (Hypothesis 3)

Results showed that light heterogeneity had a positive effect on plant species richness $\left(\mathrm{p}=0.005, \mathrm{r}^{2}=0.57\right.$, fig. 6). The heterogeneity of potassium correlated slightly positively with increasing plant species richness, but this relationship was not statistically significant when outliers were removed (excluding all values above $1.5 *$ interquartile range).

\section{Effects of structural complexity on plant species richness (Hypothesis 4)}

Among the variables which represent the structural variation of the stand, only the SSCI had an effect on species richness $\left(\mathrm{p}=0.008 \mathrm{r}^{2}=0.44\right.$ Fig. 7$)$ while DBHsd and TRI had no effect.

Discussion

\section{Light quantity determines understory plant layer diversity (Hypothesis 1)}

We found that light explained most of the variation in understory species richness, and that species richness asymptotically increases with light availability. Thus, we support the generally accepted view of light quantity being the most important driver of composition and diversity of understory plant species (e.g. Márialigeti 
et al. 2016). In forest understories, light is a limited resource for many plant species as species richness increases with increasing light. Nevertheless, this relationship was humpbacked as species richness reached a plateau and started to decline above $40 \%$ to $50 \%$ light availability. However, there were few data above $50 \%$ light so we have to be careful about making strong inferences regarding the decline in understory plant species richness above $50 \%$ light. Of course, plant species richness in the understory is not only controlled by light. Among the other resources tested, $\mathrm{pH}$ also showed a hump-shaped relationship with species richness. An increase in species richness with increasing pH is widely accepted (Grime and others 1973, Ewald 2003, Hofmeister et al. 2009, Leuschner et al. 2017). Surprisingly, species richness decreased at moderately high pH values ( pH 6) in our study. Plant diversity slightly decreased with increasing soil C:N-ratio, while neither $\mathrm{C}$ nor $\mathrm{N}$ concentrations in soil were correlated with species richness. We suggest that this decrease is related to the prevailing forms of stand humus, with mull-type (low soil C:N ratios, rather high $\mathrm{pH}$ values) forest communities harbouring generally more understory species than raw humus or moder type communities with high C:N ratios and relatively low pH (Leuschner et al. 2017).

\section{Structurally complex canopies create heterogeneity in resource availability (Hypothesis 2)}

We confirmed our second hypothesis that structurally complex canopies increase heterogeneity of light and soil resources at the forest floor. The structural complexity of the tree canopy influenced the distribution of light within forests in space and time. In this study, structural complexity increased with an increasing number of gaps in the canopy, resulting in an heterogenous diversity of moving sun flecks at the forest floor. In these sun flecks, the amount of light can be over two orders of magnitude higher than in the shade (Chazdon and Pearcy 1991). This can be beneficial for some species which are able to handle the sudden increase, or detrimental for those which are sensitive to full sunlight. As the sun is moving during the day, the spatial configuration of leaves, twigs and stems will affect how long a certain spot or certain plant will be irradiated. Furthermore, the different incidence angles of the sun during the year will influence the spatial alignment of the sun flecks. This also affects in which phenological stage a plant is standing in full light or shade. Hence, on a very small scale numerous species could be adapted to the many different light conditions present over space and time. For soil resources, we found that C:N ratio and potassium content increased with canopy complexity, particularly for SSCI and DBHsd. A higher canopy complexity causes a heterogeneous distribution of plant material in forest stands. In combination with heterogeneous light distribution on the forest floor and eventually heterogeneous water input, decomposition of organic matter is altered at the small scale level which leads to heterogeneity of the C:N ratio. In addition, DBHsd also increased light heterogeneity. As the DBH is strongly correlated with tree age, results imply that a stand with different age classes will increase light heterogeneity. The correlation of potassium with canopy complexity was very weak although it is possible there is a covariance with other variables.

\section{Resource heterogeneity increases plant diversity (Hypothesis 3)}

The heterogeneity-diversity relationship is one of the central hypotheses explaining the diversity of plant species. It states that environmental heterogeneity should prevent competitive equilibrium, increasing the available niche space and thus allowing more species to coexist (Huston 1979, Tokeshi 2009). Although it is often tested at the macro-ecological scale (Stein et al. 2014), it should in principle be applicable at smaller scales as well. In terms of light conditions, this hypothesis predicts coexistence of species that are adapted to different levels of light. Our findings generally support this view. Species richness was found to increase with light heterogeneity. To our knowledge, only one other study(Reich et al. 2012) explicitly tested the heterogeneity-diversity hypothesis for light with direct measurements of light heterogeneity. In that study, understory species richness was also found to increase with increasing light heterogeneity.

Light heterogeneity increased species richness significantly, while the heterogeneity of other resources such as soil $\mathrm{pH}, \mathrm{C}: \mathrm{N}$ ratio, $\mathrm{P}$ and $\mathrm{K}$ did not. This finding can be explained in two ways: either the scale was not suitable (see above, i.e. if grain size of heterogeneity in soil resources does not match the sampling size of the plant community), or the level of heterogeneity was simply not large enough to provide different resource niches for understory plants. Moreover, among tested resources, light was the most important factor for 
increased species richness. Possibly there is a link between the importance of a resource and the effect of its heterogeneity on species richness.

\section{Canopy complexity begets plant diversity (Hypothesis 4)}

We have shown that the structural complexity of the forest canopy results in spatio-temporal heterogeneity of light conditions at the forest floor. We have further shown that this heterogeneity in light conditions promotes plant species richness. These findings suggest that the determination of canopy complexity by remote sensing techniques might have considerable potential for predicting environmental conditions and understory plant diversity of forests. Former studies have shown that the structural complexity index SSCI, which was also used here, reliably predicts important microclimatic parameters such as diurnal temperature and vapour pressure differences (Ehbrecht et al. 2019). Getzin et al. (2012) found a significant relationship between gap size and species richness, which points to the importance of light availability for species richness in forests. Nevertheless, for both a mechanistic understanding of ecosystem functioning and nature conservation, not only the number of species present, but also species composition, including the occurrence of dominant or rare species, are important aspects of local biodiversity. Thus, methods for indirectly predicting species richness will never replace field surveys, but may be helpful under certain circumstances, as in remote areas or inaccessible terrains.

This study indicates that both light quantity and heterogeneity at the microscale positively affect understory plant species diversity in mountainous temperate forests of Germany. By confirming the heterogeneitydiversity hypothesis, we were able to answer a fundamental research question. However, these results also have important practical implications for how best to manage these forests to maintain understory plant diversity. As plants are primary producers and are important for many other species at higher trophic levels, it is essential to preserve or enhance plant diversity in the understory. In this study the relationship found between canopy crown complexity and light heterogeneity suggests that understory plant diversity could be increased in forests managed by single tree harvesting by spatially varying the quantities of trees to be logged to create more heterogenous understory light environment.

Acknowledgements - We are grateful to the foresters of the state of Baden-Württemberg for the provided facilities in the forests. We thank Ilse Storch and Johannes Penner for the coordination of ConFoBi. Further, we thank Lana Ruddick for language revision.

Funding - This study was funded by the German Research Foundation (DFG) within the Research Training Group ConFoBi (grant number GRK 2123/1 TPX) and a scholarship from the Internationale Graduiertenakademie (IGA) at University of Freiburg to JH.

Data accessibility statement - The data that support the findings of this study are openly available in Dryad Digital Repository. (Data will be uploaded by acceptance of the manuscript)

References

Abd Latif, Z. and Blackburn, G. A. 2010. The effects of gap size on some microclimate variables during late summer and autumn in a temperate broadleaved deciduous forest. - Int. J. Biometeorol. 54: 119-129.

Allouche, O. et al. 2012. Area-heterogeneity tradeoff and the diversity of ecological communities. - Proc. Natl. Acad. Sci. 109: 17495-17500.

Ampoorter, E. et al. 2015. Disentangling tree species identity and richness effects on the herb layer: first results from a German tree diversity experiment. - J. Veg. Sci. 26: 742-755.

Ampoorter, E. et al. 2016. Driving mechanisms of overstorey-understorey diversity relationships in European forests. - Perspect. Plant Ecol. Evol. Syst. 19: 21-29.

Angert, A. L. et al. 2009. Functional tradeoffs determine species coexistence via the storage effect. - Proc. Natl. Acad. Sci. U. S. A. 106: 11641-11645. 
Aubry, K. B. et al. 2009. Variable-retention harvests in the Pacific Northwest: A review of short-term findings from the $\{$ DEMO $\}$ study. - For. Ecol. Manag. 258: 398-408.

Baethgen, W. E. and Alley, M. M. 1989. A manual colorimetric procedure for measuring ammonium nitrogen in soil and plant Kjeldahl digests. - Commun. Soil Sci. Plant Anal. 20: 961-969.

Bartels, S. F. and Chen, H. Y. H. 2010. Is understory plant species diversity driven by resource quantity or resource heterogeneity? - Ecology 91: 1931-1938.

Bartoń, K. 2019. MuMIn: Multi-Model Inference - R package version 1.6 (2019).

Bates, D. et al. 2015. Fitting Linear Mixed-Effects Models Using lme4. - J. Stat. Softw. 67: 1-48.

Bengtsson, J. et al. 2000. Biodiversity, disturbances, ecosystem function and management of European forests. - For. Ecol. Manag. 132: 39-50.

Bergholz, K. et al. 2017. Environmental heterogeneity drives fine-scale species assembly and functional diversity of annual plants in a semi-arid environment. - Perspect. Plant Ecol. Evol. Syst. 24: 138-146.

Charrad, M. et al. 2014. NbClust: An R Package for Determining the Relevant Number of Clusters in a Data Set. - J. Stat. Softw. 61: 1-36.

Chazdon, R. L. and Pearcy, R. W. 1991. The Importance of Sunflecks for Forest Understory Plants. BioScience 41: 760-766.

Chesson, P. 2000. Mechanisms of Maintenance of Species Diversity. - Annu. Rev. Ecol. Syst. 31: 343-366.

Connell, J. H. 1978. Diversity in Tropical Rain Forests and Coral Reefs. - Science 199: 1302-1310.

Delignette-Muller, M. L. and Dutang, C. 2015. fitdistrplus: An R Package for Fitting Distributions. - J. Stat. Softw. 64: 1-34.

Duguid, M. C. and Ashton, M. S. 2013. A meta-analysis of the effect of forest management for timber on understory plant species diversity in temperate forests. - For. Ecol. Manag. 303: 81-90.

Ehbrecht, M. et al. 2017. Quantifying stand structural complexity and its relationship with forest management, tree species diversity and microclimate. - Agric. For. Meteorol. 242: 1-9.

Ehbrecht, M. et al. 2019. Effects of structural heterogeneity on the diurnal temperature range in temperate forest ecosystems. - For. Ecol. Manag. 432: 860-867.

Ewald, J. 2003. The calcareous riddle: Why are there so many calciphilous species in the Central European flora? - Folia Geobot. 38: 357-366.

Fedrowitz, K. et al. 2014. Can retention forestry help conserve biodiversity? A meta-analysis (C Baraloto, Ed.). - J. Appl. Ecol. 51: 1669-1679.

Forrester, D. I. et al. 2018. Effects of crown architecture and stand structure on light absorption in mixed and monospecific Fagus sylvatica and Pinus sylvestris forests along a productivity and climate gradient through Europe. - J. Ecol. 106: 746-760.

Frey, J. et al. 2018. UAV Photogrammetry of Forests as a Vulnerable Process. A Sensitivity Analysis for a Structure from Motion RGB-Image Pipeline. - Remote Sens. 10: 912.

Getzin, S. et al. 2012. Assessing biodiversity in forests using very high-resolution images and unmanned aerial vehicles. - Methods Ecol. Evol. 3: 397-404.

Grime, J. P. and others 1973. Competitive exclusion in herbaceous vegetation. - Nat. UK 242: 344-347.

Gustafsson, L. et al. 2012. Retention Forestry to Maintain Multifunctional Forests: A World Perspective. BioScience 62: 633-645. 
Gustafsson, L. et al. 2019. Retention as an integrated biodiversity conservation approach for continuouscover forestry in Europe. - Ambio 49: 85-97.

Halpern, C. B. et al. 2012. Level and pattern of overstory retention interact to shape long-term responses of understories to timber harvest. - Ecol. Appl. 22: 2049-2064.

Hardin, G. 1960. The Competitive Exclusion Principle. - Science 131: 1292-1297.

Hofmeister, J. et al. 2009. The influence of light and nutrient availability on herb layer species richness in oak-dominated forests in central Bohemia. - Plant Ecol. 205: 57.

Huston, M. 1979. A General Hypothesis of Species Diversity. - Am. Nat. 113: 81-101.

Hutchinson, G. E. 1957. Concluding Remarks. - Cold Spring Harb. Symp. Quant. Biol. 22: 415-427.

Kriebitzsch, W.-U. et al. 2013. Forest-specific diversity of vascular plants, bryophytes, and lichens. In: Integrative approaches as an opportunity for the conservation of forest biodiversity (D Kraus and F Krumm, Eds.). - European Forest Institute Freiburg.

Legendre, P. and Gallagher, E. D. 2001. Ecologically meaningful transformations for ordination of species data. - Oecologia 129: 271-280.

Leuschner, C. et al. 2017. Vegetation ecology of Central Europe. Volume I.

Liira, J. et al. 2007. The forest structure and ecosystem quality in conditions of anthropogenic disturbance along productivity gradient. - For. Ecol. Manag. 250: 34-46.

Lindenmayer, D. B. et al. 2012. A major shift to the retention approach for forestry can help resolve some global forest sustainability issues. - Conserv. Lett. 5: 421-431.

Lundholm, J. T. 2009. Plant species diversity and environmental heterogeneity: spatial scale and competing hypotheses. - J. Veg. Sci. 20: 377-391.

MacArthur, R. H. and MacArthur, J. W. 1961. On Bird Species Diversity. - Ecology 42: 594-598.

MacArthur, R. and Levins, R. 1967. The Limiting Similarity, Convergence, and Divergence of Coexisting Species. - Am. Nat. 101: 377-385.

Márialigeti, S. et al. 2016. Environmental drivers of the composition and diversity of the herb layer in mixed temperate forests in Hungary. - Plant Ecol 217: 549-563.

Mehlich, A 1953. Rapid determination of cation and anion exchange properties and pHe of soils. - J. Assoc. Off. Agric. Chem. 11: 445-457.

Miranda, K. M. et al. 2001. A Rapid, Simple Spectrophotometric Method for Simultaneous Detection of Nitrate and Nitrite. - Nitric Oxide 5: 62-71.

Morzaria-Luna, H. et al. 2004. Relationship between Topographic Heterogeneity and Vegetation Patterns in a Californian Salt Marsh. - J. Veg. Sci. 15: 523-530.

Murtagh, F. and Legendre, P. 2014. Ward's Hierarchical Agglomerative Clustering Method: Which Algorithms Implement Ward's Criterion? - J. Classif. 31: 274-295.

Nakagawa, S. and Schielzeth, H. 2013. A general and simple method for obtaining R2 from generalized linear mixed-effects models. - Methods Ecol. Evol. 4: 133-142.

Richard, M. et al. 2000. Environmental Heterogeneity and the Spatial Structure of Fern Species Diversity in One Hectare of Old-Growth Forest. - Ecography 23: 231-245.

Reich, P. B. et al. 2012. Understorey diversity in southern boreal forests is regulated by productivity and its indirect impacts on resource availability and heterogeneity. - J. Ecol. 100: 539-545. 
Rothmaler 2017, Exkursionsflora von Deutschland. Gefäßpflanzen: Grundband, (EJ Jäger, Ed.). - Springer Spektrum.

Schleppi, P. et al. 2007. Correcting non-linearity and slope effects in the estimation of the leaf area index of forests from hemispherical photographs. - Agric. For. Meteorol. 144: 236-242.

Sedio, B. E. and Ostling, A. M. 2013. How specialised must natural enemies be to facilitate coexistence among plants? - Ecol. Lett. 16: 995-1003.

Silvertown, J. 2004. Plant coexistence and the niche. - Trends Ecol. Evol. 19: 605-611.

Stein, A. et al. 2014. Environmental heterogeneity as a universal driver of species richness across taxa, biomes and spatial scales. - Ecol. Lett. 17: 866-880.

Storch, I. et al. 2020. Evaluating the effectiveness of retention forestry to enhance biodiversity in production forests of Central Europe using an interdisciplinary, multi-scale approach. - Ecol. Evol. 10: 1489-1509.

$\mathrm{Su}$, X. et al. 2019. Forest Understorey Vegetation: Colonization and the Availability and Heterogeneity of Resources. - Forests 10: 944.

Taboada, Á. et al. 2008. Plant and carabid beetle species diversity in relation to forest type and structural heterogeneity. - Eur. J. For. Res. 129: 31.

Tamme, R. et al. 2010. Environmental heterogeneity, species diversity and co-existence at different spatial scales. - J. Veg. Sci. 21: 796-801.

Tokeshi, M. 2009. Species Coexistence: Ecological and Evolutionary Perspectives. - John Wiley \& Sons.

Venables, W. N. and Ripley, B. D. 2002. Modern Applied Statistics with S. - Springer.

Wilson, M. F. J. et al. 2007. Multiscale Terrain Analysis of Multibeam Bathymetry Data for Habitat Mapping on the Continental Slope. - Mar. Geod. 30: 3-35.

Wright, J. S. 2002. Plant diversity in tropical forests: a review of mechanisms of species coexistence. Oecologia 130: 1-14..

Zielewska-Büttner, K. et al. 2016. Automated Detection of Forest Gaps in Spruce Dominated Stands Using Canopy Height Models Derived from Stereo Aerial Imagery. - Remote Sensing 8: 175. 


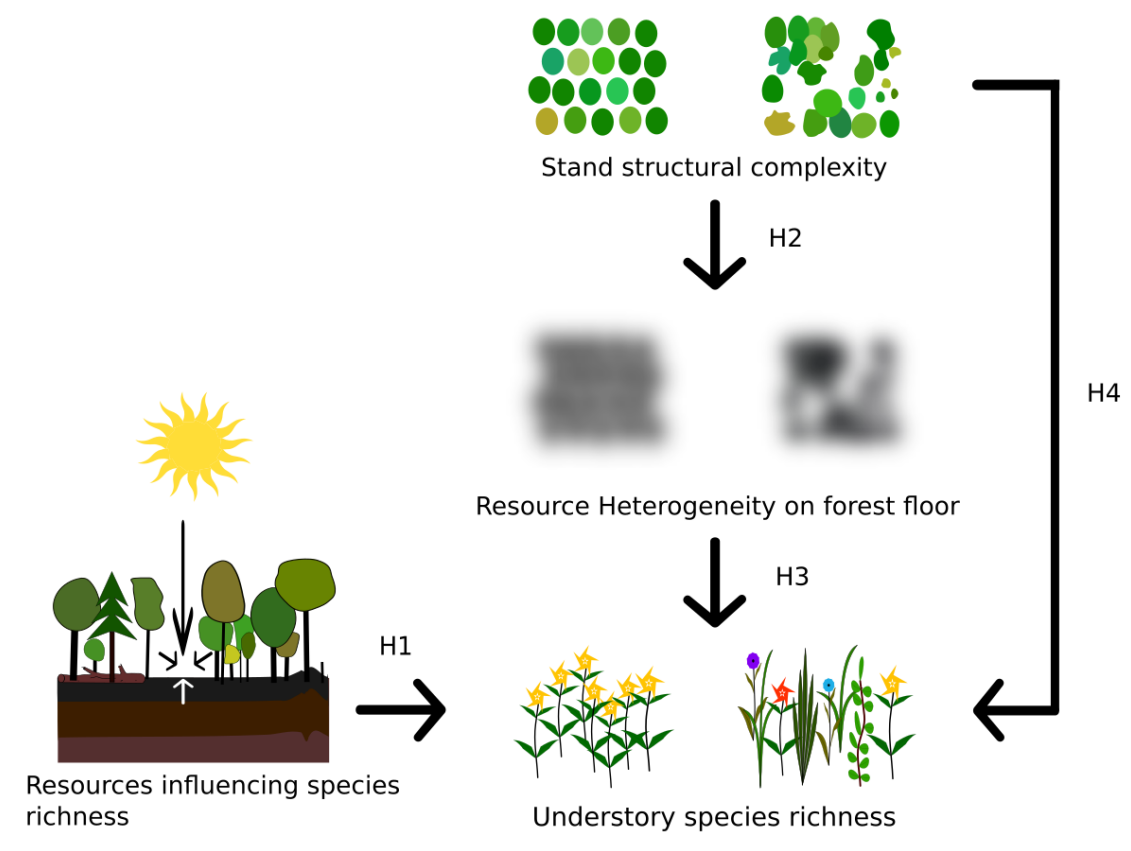




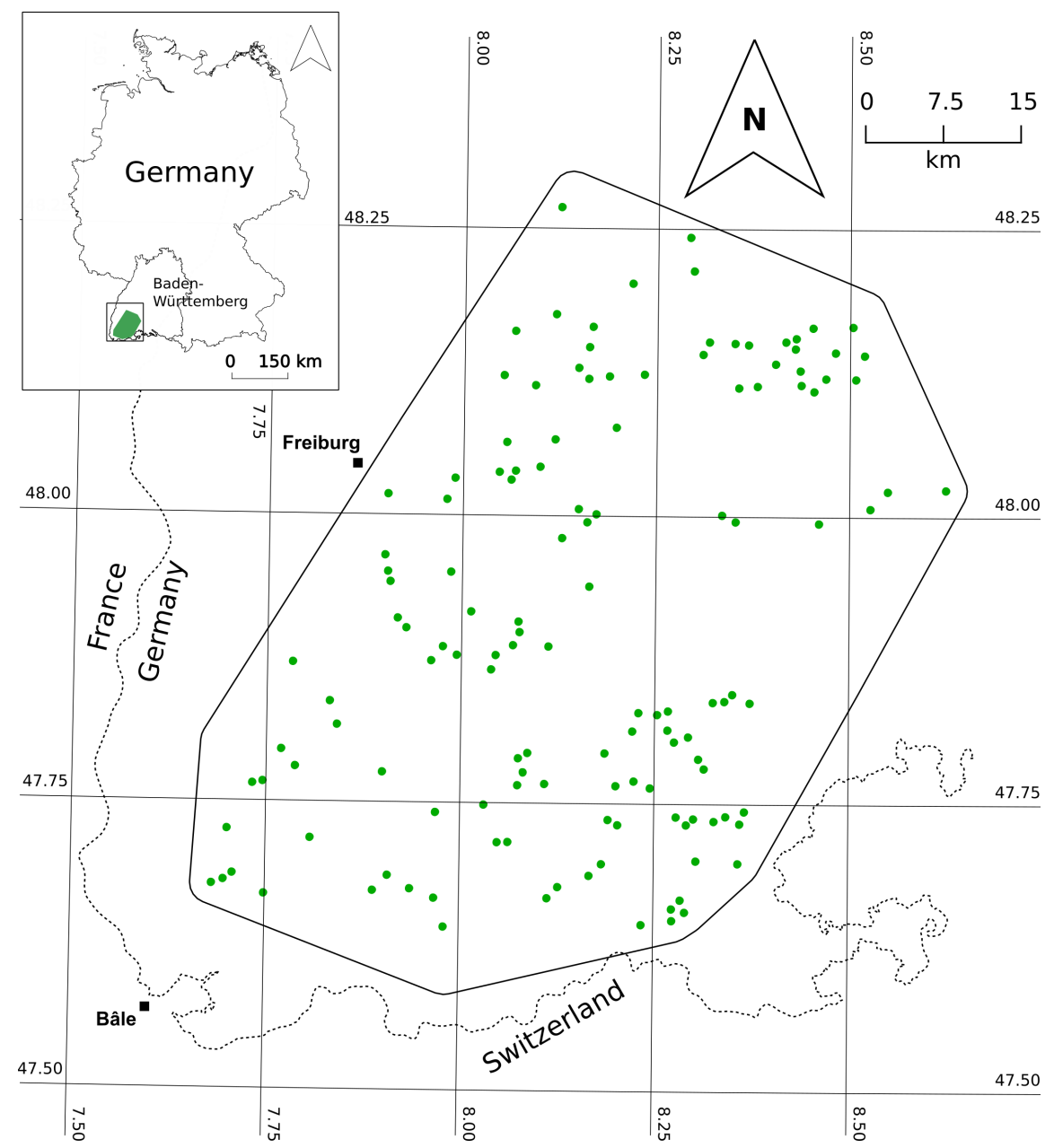



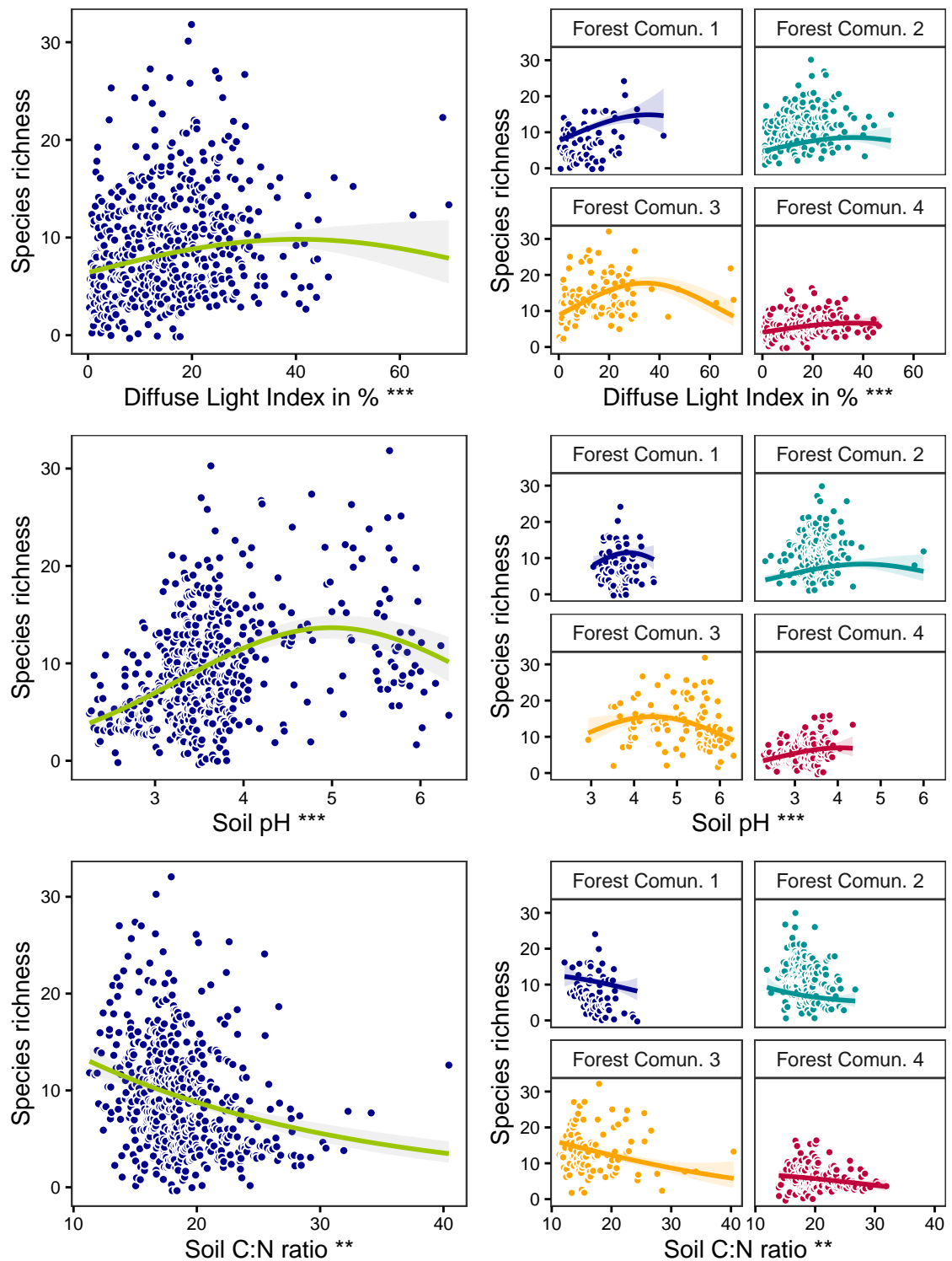

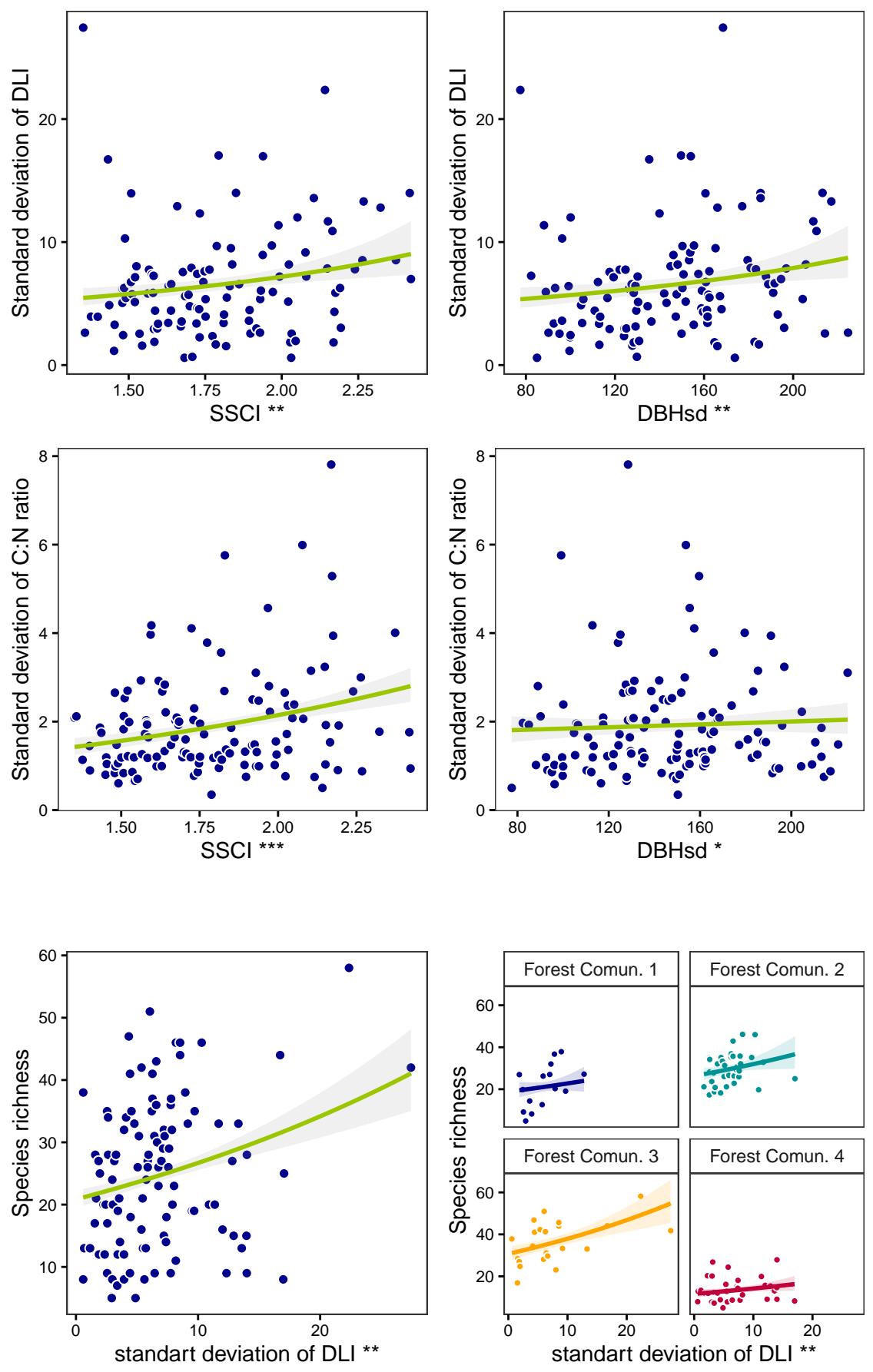

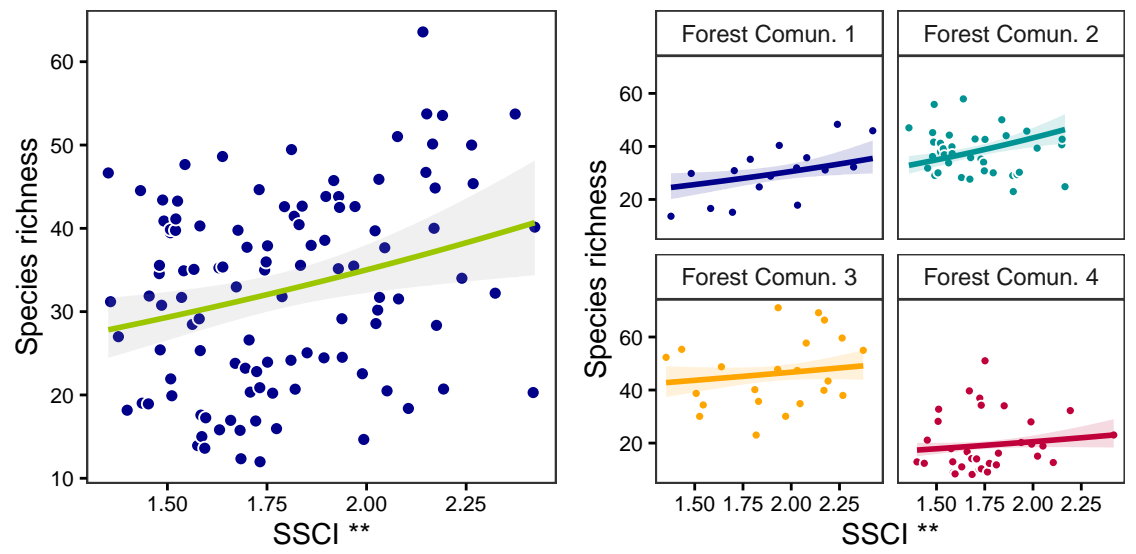